\title{
Mapping the Austrian political spectrum with the help of VAAs
}

\author{
Sebastian Jäckle ${ }^{1, *}$, Pascal D. König ${ }^{2, * *}$ \\ 1 Seminar für Wissenschaftliche Politik, Universität Freiburg \\ 2 Institut für Politikwissenschaft, Goethe-Universität Frankfurt am Main \\ * sebastian.jaeckle@politik.uni-freiburg.de \\ ** p.koenig@soz.uni-frankfurt.de
}

\begin{abstract}
This paper uses data from the Austrian Voting Advice Application (VAA) wahlkabine.at to locate parties in policy spaces for the 2006, 2008, 2013 and 2017 national elections. It formulates an approach that combines positional information from the VAA data with information about issue saliences that stems from the VAA itself as well as from manifestos coded by the regularly conducted Austrian National Election Study. The VAA-inherent and the external weights serve to calibrate party policy spaces that underlie the VAA data. The paper depicts the Austrian political party space by means of a two-dimensional multidimensional scaling (MDS) map, and furthermore assesses the usefulness of the twoweighting procedures. The findings suggest that the use of the internal weights cannot make much of a difference in the present form. In contrast, the external weights not only alter the structure of the party space but also enhance the confidence in the results for substantial reasons.
\end{abstract}

\section{Keywords}

Voting Advice Applications, party positions, Austrian national elections, scaling, wahlkabine

\section{Die Kartierung des österreichischen Parteienraums anhand der Wahlempfehlungshilfe wahlkabine.at}

\section{Zusammenfassung}

Der Beitrag nutzt Daten der österreichischen Wahlempfehlungshilfe wahlkabine.at, um die Parteipositionen für die Nationalratswahlen der Jahre 2006 bis $2017 \mathrm{zu}$ bestimmen. Er formuliert einen Ansatz, der die Positionsinformationen der Wahlempfehlungshilfe mit zwei Arten von Themensalienzen kombiniert: Mit internen aus der Wahlempfehlungshilfe selbst sowie mit externen aus Wahlprogrammen, die im Rahmen der Österreichischen Wahlstudie kodiert wurden. Die Salienzen dienen der Kalibrierung der zugrundeliegenden Parteienräume. Neben der Darstellung des österreichischen Parteienraums anhand einer zweidimensionalen Multidimensionalen Skalierung (MDS) prüft die Analyse damit auch den generellen Nutzen dieser Gewichtungsverfahren. Die Befunde zeigen, dass die aus wahlkabine.at selbst entnommenen Gewichte kaum Einfluss haben. Stattdessen ändern die externen Themengewichte die Struktur des Parteienraums und sind dabei eine Quelle, die inhaltlich eine bessere Abbildung der Parteipositionen begründet.

\section{Schlüsselwörter}

Voting Advice Applications, Wahlempfehlungshilfen, Parteipositionen, Nationalratswahlen, Skalierung, wahlkabine

The authors have declared that no competing interests exist. 


\section{Introduction}

Voting Advice Applications (VAAs) have been around for about I5 years. These online-tools such as the German Wahl-O-Mat, the Dutch StemWijzer or the Swiss smartvote have been developed to help voters find out how political parties (or candidates) match their political preferences. Due to their ease of use, a substantial number of voters nowadays employs these online-tools. For example, more than $4 \mathrm{~m}$ people used the StemWijzer before the 2012 elections in the Netherlands and more than $15 \mathrm{~m}$ the Wahl-O-Mat ahead of the German national election in 20I7. Research on VAAs has mostly dealt with their effects on political knowledge (Schultze 20I4), issue voting (Ladner 20I6), voter turnout (Fivaz and Nadig 20IO; Marschall and Schultze 20I2), electoral preferences (Mahéo 20I6; Walgrave, van Aelst, and Nuytemans 2008; Kleinnijenhuis et al. 20I7) as well as with the impact of design choices on the recommendations given to voters (Germann et al. 2015; Rosema and Louwerse 2016; Agathokleous and Tsapatsoulis 2016; Katakis et al. 2014).

This article takes a different perspective. Its aim is to use data from the Austrian VAA wahlkabine.at to position politically relevant parties, which took part in the last four national elections (2006, 2008, 2013 and 2017) and thus in over a decade of notable political developments, within an ideological space. It does so by combining information about both the salience of specific policy issues and the positions parties take on these issues. Existing ways of estimating party positions usually (but see Kriesi et al. 2006; Bornschier 2010; Warwick 2006) either rely on positional information - as in the case of expert surveys (Laver and Hunt 1992; Benoit and Laver 2006; Polk et al. 20I7) - or are based on text analysis that translates the relative saliency of issues (Müller et al. 20I7; Volkens et al. 20I7) or words (Laver, Garry, and Benoit 2007; Proksch and Slapin 2009) into party positions. While these existing approaches exhibit some commonalities in their measurements, they often also do not yield converging results, as Dolezal et al. (2016, 646) have recently shown for the Austrian political parties' left-right positions between 2002 and 2008.

By mapping the Austrian party policy space for several elections, this article thus also addresses the measurement of party position as a classic political science problem and illustrates the usefulness of VAA-data for that purpose. The Austrian case offers particularly suitable conditions for making use of information about both saliencies and positions. First, the Austrian VAA wahlkabine.at not only contains information about parties' stances regarding a range of specific policies, but also comprises parties' importance ratings with respect to these policies. These VAA-internal importance ratings will be used to weigh the individual policy positions of wahlkabine.at in order to more accurately position parties in a low dimensional space. Second, the regularly conducted Austrian National Election Study comprises a content analysis of party manifestos (Müller et al. 20I7) that offers information about parties' issues importance. We use this information as external weights to compare them to the VAA inherent issue weights and examine whether these different weights lead to similar or different party policy spaces.

Based on the comparison of the results obtained with the unweighted data and the two weighting methods (internal and external saliency weights), the paper discusses how VAAs should be designed in order to provide for a meaningful basis to measure party positions for political scientists. This is of relevance not merely to scholars of party politics who may, as for instance in the Austrian context, want to use information about party positions to analyse party competition and coalition building (Müller and Jenny 2000; Müller and Fallend 2004; Dolezal et al. 20I4) or pledge fulfilment in coalition agreements (Schermann and Ennser-Jedenastik 20I4a, 20I4b; Praprotnik 20I5). The results can also help to provide voters with advice that is more closely attuned to the party space in their countries as it is constituted by parties' positions and issue saliences. Beyond the question of VAA design, we also discuss some more general implications for the analysis and interpretation of party positions and point to further applications in which the proposed approach of weighting policy items from a VAA promises to offer an added value.

\section{Measuring party positions by means of VAAs}

At first glance, VAAs seem particularly suited for the study of party positions given that these tools contain information about parties' stances on individual issues. Are they for or against a minimum wage? Do they support or oppose renewable energies? Of course, positions on such individual issues do not say anything about party positions in a more general sense yet, i.e. in terms of how they differ regarding their overall programmatic profiles. However, the entirety of information from a range of such issues taken together allows for extracting a larger pattern of how parties position themselves in relation to one another and to locate them in a low-dimensional space. This is possible through condensing the VAA-information in a way that yields an overall pattern of commonalities and opposition among the parties.

To generate a structure of party interrelations based on VAA information about parties' positions regarding individual policies, previous studies have employed scaling methods in order to bundle the various policy items contained in a VAA. Several studies have, however, not drawn on the party positions provided with the VAA for these scaling procedures. Rather, they have employed 
user input data about their policy position and used scaling techniques to scale these responses and extract larger programmatic dimensions (Louwerse and Rosema 2014; Wheatley 20I2; Wheatley, Carman, Mendez, and Mitchell 20I4). Also by knowing the party affiliation of these users, one can position parties indirectly on those extracted dimensions by calculating average user positions grouped by party affiliation.

Alternatively, it is possible to directly use information about party positions on individual policies. Previous work in that regard has either simply counted the amount of concurrent items between parties (Naumann 2017) or again used scaling methods to map party positions in a low-dimensional space (Gemenis 2013; Talonen and Sulkava 201I; Wagschal and König 2014; König and Jäckle 20I8). This approach of scaling VAA data has a major advantage which however has a potentially great weakness as its flipside. On the one hand, the VAA issues are chosen specifically with a view to a given election - and can thus be expected to adequately represent those issues that were relevant at the election date. This, on the other hand, implies that the extracted party policy spaces and party positions cannot straightforwardly be compared between elections as the generated dimension and their meaning are not fixed but differ between elections.

Moreover, the election-specific selection of issues could be criticized as arbitrary. After all, one could always think of different selections of relevant issues for a given election; and depending on the selection of concrete VAA issues, which are tied to larger issue domains like welfare or law and order, one gets different implicit weightings of such issue domains. For instance, it could be the case that during an election campaign, parties have put a strong emphasis on social security and welfare while this issue domain is represented in the VAA with only a single item among several dozen. The selection of VAA issues thus creates a problem because when extracting party positions based on the data contained in the VAA using structure-identifying methods, the results will depend on the number and choice of the VAA items (Gemenis 2013, 280). In addition, previous research has shown that varying the selection of issues in a VAA can quickly lead to differing recommendations for people who use that tool (Walgrave, van Aelst, and Nuytemans 2008).

This problem may not be a grave one in the actual practice of using VAAs for obtaining voting advice. After all, users of some VAAs have the possibility of either skipping items they deem irrelevant and of attributing weights to VAA items more or less in accordance with their own issue importance perceptions. This feature can potentially counter a bias in the selection of VAA items as it allows to calibrate the item saliencies through aligning them with voters' own saliencies. However, in the same way that issue salience matters for individual voters' party perceptions, issue salience also matters on the level of the party system and the party positions. The basic idea here is simple: if two parties agree or disagree on an issue that is highly important in party competition, this issue would have to be reflected in the interparty relations more strongly than other issues that are less relevant.

Against the backdrop of these considerations, the Austrian VAA wahlkabine.at deserves particular attention. This tool not only contains information about how parties position themselves on individual issues, but also about how parties rate the importance of these issues or items. These item importance scores can in turn be used to calibrate the party positions. This approach amounts to using internal weights of the VAA to achieve a better representation of party policy positions.

In order to take into account the importance that parties give to various relevant issues, one does not have to rely on their own ratings though. Instead, it is also possible to look at the extent to which they emphasize issues in their manifestos. Again, the Austrian context proves to have particular merit because of the data collected by the Austrian National Election Study (www.autnes.at). One of the components of this regularly conducted study is a content analysis of party manifestos that draws on categories for coding topics and positions. As a result, this study provides information about the importance that parties give to a comprehensive range of policy-issues. Using this information for the calibration of VAA data amounts to employing external weights in order to align the implicit issue domain weights resulting from the selection of VAA items with parties' issue saliencies.

Altogether, making use of the data sources described above is advantageous in that it allows to clearly distinguish between an issue's saliency and parties' positions regarding it. Furthermore, relying on the VAA data for the party positions has the additional merit that we can directly compare parties' ideological stances since all parties have to answer to a set of question that they all receive. This is much more difficult when the party positions are extracted from manifestos in which the parties have the opportunity to mask their real positions by hardly mentioning certain policy issues at all.

\section{The Austrian wahlkabine.at}

The Austrian VAA wahlkabineat was launched for the first time before the 2002 general elections. Since then, it has been used for a total of 39 elections at the state, national and European level (as of November 20I7). With more than $5 \mathrm{~m}$ users in total and more than $1.2 \mathrm{~m}$ just for the 2017 elections, it is also the most widely used VAA in Austria. The process of its creation is similar to other 
VAAs: First, an editorial team that consists of journalists and experts from political science, cultural studies and methodology develops a catalogue of about 40 questions which is sent to all competing parties. The parties answer these questions with "yes" or "no", explicate their positions and indicate on a three-point-scale for how important they deem the various issues. Subsequently, the editorial team discusses the answers and chooses 26 questions (25 questions in 2013) for the final online-tool.

VAA-users can give their positions on the 26 items answering with "yes", "no" and "not specified". Additionally, they can rate the importance of the policy-issue on a nine-point-scale. Having answered all 26 questions respondents get presented the highest matches between their own ideological stances and the parties' positions. The calculation of these matches also takes into account the item-weights by the parties as well as by the users (wahlkabine.at 20I7).

\section{Obtaining issue saliencies from wahlkabine.at and AUTNES}

The scaling analysis below makes use of two sources for parties' issue saliencies in order to calibrate the data from wahlkabine.at: (I) the VAA-internal item importance rating by the parties themselves and (2) external saliencies calculated from the coding of party manifestos that forms part of the AUTNES-project. Such information about item saliences can be used to weigh the distances between two parties on the various items and to generate weighted overall (dis-)similarities between parties. This information about similarities can then be employed in the scaling procedure described below. While this weighting process is the same for all weights, the weights themselves are generated differently.

The internal importance scores (I to 3) are already given in the VAA for the individual items and can directly be used to weigh party differences on each of the 26 items. Two different weighting procedures will be applied for them, one weighting the distances by the overall internal importance scores (averaged over all parties) and one by the importance scores of the two parties whose

I In some cases the simplification coming along with this binary response set yields assignments that are at first sight implausible. When for example the FPÖ supports sea rescue operations in the Mediterranean for refugees just as the Greens, the SPÖ, the NEOS or the KPÖ this comes as a surprise, yet looking at the given reasons it makes sense. The FPÖ links their support for sea rescue operations with the demand to return the rescued persons directly to North Africa. The different reasons for their "yes" for FPÖ and the left parties for this item can nevertheless not be taken into account when measuring the party positions based on the VAA data. This problem also biases the VAA results when matching the users to the parties. Yet, a critical inspection of all items shows that such implausibilities are very rare and potentially do not bias the overall results in a significant way. distance is measured (averaged pairwise). The external weights based on the AUTNES data have to be calculated before they can be applied, and they have to be calculated in such a way so that they can be assigned systematically to the VAA items. The AUTNES coding data does not provide information that can directly be brought together with the individual VAA issues, but it does offer information about the salience of larger issue domains or topics. By grouping the VAA items under these topics, it is possible to match the AUTNES saliencies to the various VAA items. To obtain the final item-specific weights, we need to know the topic saliencies derived from the party manifestos and take into account the implicit weights that result from the number of VAA items per topic.

Altogether, our analysis below uses the VAA-internal weights in two variants (averaged over all parties and averaged pairwise over parties) as well as the external weights based on the AUTNES data to generate three weighted party policy spaces. As a reference, we also generate a party spaces based on the raw VAA item scores, which amounts to using the implicit topic weights (resulting from the VAA item numbers per topic). Table I gives an overview of these weights as they are applied in the scaling analysis below. An overview of the necessary steps to obtain the weights are depicted in Figure I, which we detail in the following.

Generating manifesto-based weights that can be matched to the VAA items requires, as a starting point, a unitized category scheme. As the AUTNES data already provides a set of categories for topics with which the manifestos are coded, we use these topic categories to code the VAA items. As there are only 25 or 26 items in the Austrian VAA, it is important to reliably code these items with larger topic categories, as few deviations can already lead to notable changes (for instance coding not one but two items under a given topic already gives that topic double weight). The AUTNES data is ideal in that regard because the master codebook specifies the larger topics on two more concrete sublevels. This makes it possible to match specific VAA items to AUTNES subcategories which are nested in the 13 more comprehensive topics (e.g. basic income, health and families/children/ youth as subcategories of "welfare state").

Having categorized the VAA items with topic categories and coded the party manifestos with the same topic (already provided by the AUTNES data) in a first step, the second step is to obtain the topic weights for both data sources. For the manifestos, this is done by dividing the number of sentences coded with a topic category by all coded sentences of the party manifestos (Dolezal et al. 2016, 642). These relative topic weights are then averaged over all parties so that we obtain overall topic weights for the election. For the VAA data, the policy items belonging to each topic are simply divided by the total number of items. 
Table 1: Overview of the weighting procedures

\begin{tabular}{ll}
\hline Weighting & Source \\
\hline a) Implicit weights & No weighting, raw VAA data \\
b) Internal weights (averaged over all parties) & $\begin{array}{l}\text { VAA-internal item-specific importance ratings provided by } \\
\text { parties }\end{array}$ \\
c) Internal weights (averaged pairwise) & $\begin{array}{l}\text { VAA-internal item-specific importance ratings provided by } \\
\text { parties }\end{array}$ \\
d) external weights (averaged over all parties) & $\begin{array}{l}\text { Topic saliences based on the manifesto coding of the AUTNES } \\
\text { project }\end{array}$ \\
\hline
\end{tabular}

Figure 1: Obtaining the weights

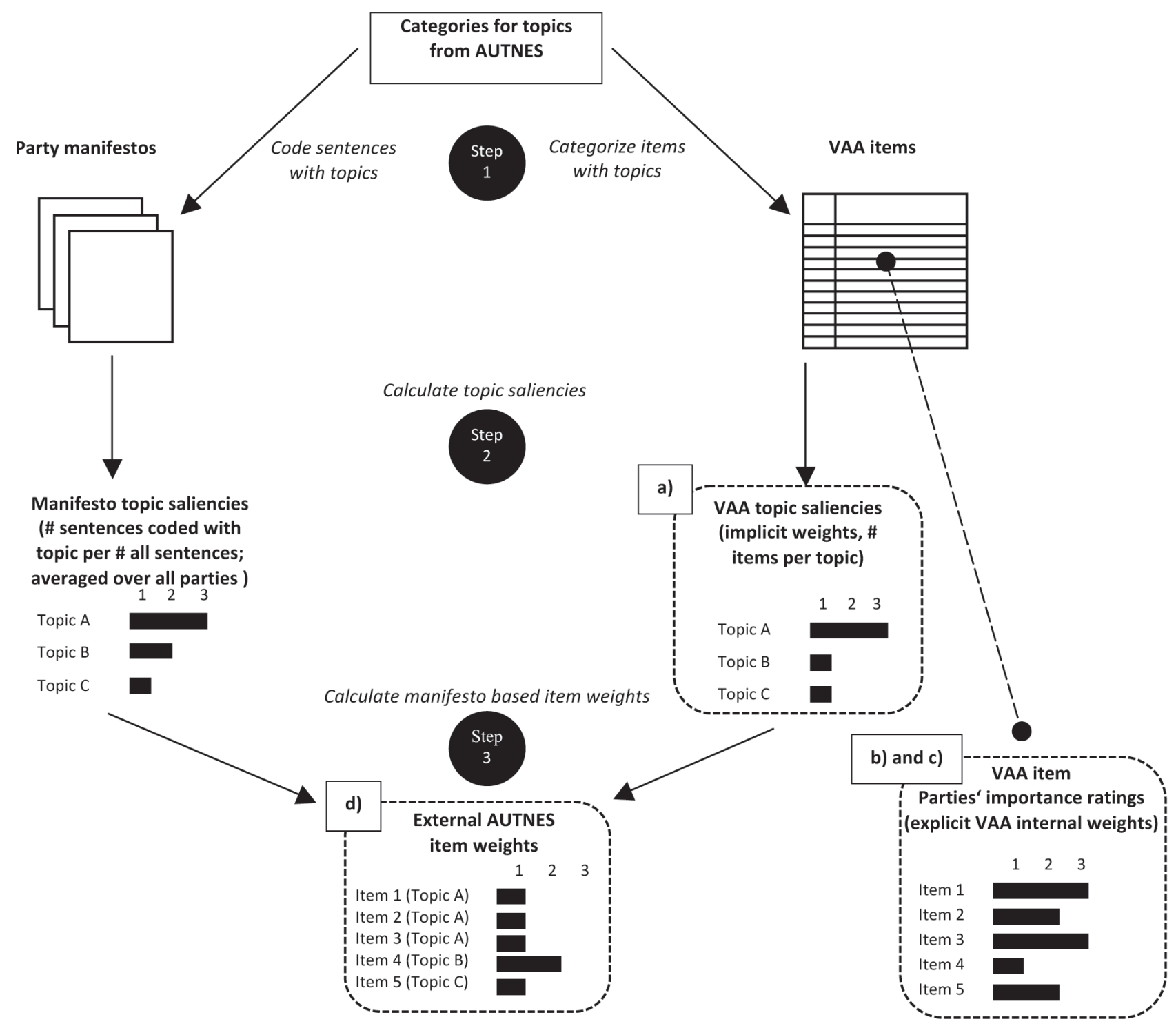


Finally (step 3), these implicit item weights can then be aligned with the topic importance based on the manifesto data. In other words, the implicit topic importance of the VAA data is transformed into the known and in that sense explicit topic importance from the manifestos. The corresponding numbers for the implicit, the internal (VAA) and the external (AUTNES) weights for all I3 topics averaged over all parties are presented by election year in Table 2 .

Looking at the table, the internal weights lead to only marginal changes in the topic weights. The correlation between these two weights (using topics as cases) is close to I for all examined elections - hence the internally weighted item importance basically mirrors the item importance that results from the item selection decisions of the VAA designers. In contrast, the AUTNES topic weights are only moderately correlated with the implicit topic weights. It thus seems that while the Austrian VAA contains information about parties' topic saliences as an extra feature, these saliences do not come close to the topic saliences expressed through party manifestos.

The most notable discrepancies in this respect can be observed for the topics "economy" and "law and order".
Moreover, while "education and culture" is generally underrepresented in the VAA compared to the manifestobased saliencies, "army" is generally overrepresented. It is furthermore striking that the European Union has not been covered in the 2013 national election and that straightforward economic issues (in line with the AUTNES coding scheme) were not contained in the VAA for the 2008 election.

The description in Table 2 is based on the internal (VAA-inherent) and external (manifesto-based) weights averaged over all parties. However, there might be marked deviations of the individual parties' topic weights according to their electoral manifestos. Taking a closer look at such possible deviations promises relevant insights in two respects. First, we can determine whether the item selection in the VAA leads to an overall implicit topic importance that starkly diverges from the topic importance of certain parties - and may thus disadvantage them. Although parties may use the Austrian VAA's item importance ratings to correct such deviations, these internal weights may not be sufficient. If, for instance, a quarter of the items belongs to the category "welfare state" a party that does not put any emphasis on that topic will

Table 2: Comparisons of the topic saliences based on raw VAA data, internal (VAA), and external (AUTNES) weights

\begin{tabular}{|c|c|c|c|c|c|c|c|c|c|c|c|}
\hline & 2006 & & & 2008 & & & 2013 & & & 2017 & \\
\hline AUTNES topics & $\begin{array}{l}\text { no } \\
\text { weights }\end{array}$ & $\begin{array}{l}\text { VAA- } \\
\text { weights }\end{array}$ & AUTNES & $\begin{array}{l}\text { no } \\
\text { weights }\end{array}$ & $\begin{array}{l}\text { VAA- } \\
\text { weights }\end{array}$ & AUTNES & $\begin{array}{l}\text { no } \\
\text { weights }\end{array}$ & $\begin{array}{l}\text { VAA- } \\
\text { weights }\end{array}$ & AUTNES & $\begin{array}{l}\text { no } \\
\text { weights }\end{array}$ & $\begin{array}{l}\text { VAA- } \\
\text { weights }\end{array}$ \\
\hline Budget & 0.00 & 0.00 & 0.04 & 0.08 & 0.08 & 0.06 & 0.04 & 0.05 & 0.06 & 0.12 & 0.12 \\
\hline Ecology & 0.00 & 0.00 & 0.04 & 0.00 & 0.00 & 0.04 & 0.04 & 0.02 & 0.03 & 0.04 & 0.05 \\
\hline Economy & 0.12 & 0.11 & 0.13 & 0.00 & 0.00 & 0.15 & 0.08 & 0.07 & 0.17 & 0.19 & 0.22 \\
\hline Education and culture & 0.12 & 0.12 & 0.13 & 0.08 & 0.08 & 0.14 & 0.08 & 0.08 & 0.14 & 0.04 & 0.05 \\
\hline Europe & 0.04 & 0.04 & 0.04 & 0.15 & 0.18 & 0.05 & 0.00 & 0.00 & 0.03 & 0.00 & 0.00 \\
\hline Foreign politics & 0.04 & 0.04 & 0.02 & 0.04 & 0.03 & 0.01 & 0.04 & 0.04 & 0.01 & 0.04 & 0.05 \\
\hline Immigration & 0.08 & 0.09 & 0.09 & 0.08 & 0.09 & 0.07 & 0.08 & 0.08 & 0.05 & 0.12 & 0.14 \\
\hline Infrastructure & 0.08 & 0.07 & 0.05 & 0.04 & 0.03 & 0.06 & 0.00 & 0.00 & 0.04 & 0.00 & 0.00 \\
\hline Institutional reform & 0.15 & 0.13 & 0.03 & 0.04 & 0.03 & 0.06 & 0.08 & 0.08 & 0.10 & 0.04 & 0.04 \\
\hline Military & 0.04 & 0.04 & 0.03 & 0.04 & 0.04 & 0.01 & 0.08 & 0.08 & 0.01 & 0.12 & 0.13 \\
\hline Security & 0.12 & 0.12 & 0.06 & 0.15 & 0.13 & 0.06 & 0.16 & 0.17 & 0.03 & 0.08 & 0.09 \\
\hline Society & 0.12 & 0.11 & 0.08 & 0.04 & 0.04 & 0.09 & 0.16 & 0.15 & 0.07 & 0.04 & 0.03 \\
\hline Welfare state & 0.12 & 0.13 & 0.21 & 0.27 & 0.28 & 0.18 & 0.16 & 0.17 & 0.18 & 0.19 & 0.17 \\
\hline $\begin{array}{l}\text { Correlations with } \\
\text { "no weights" }\end{array}$ & & 0.97 & 0.50 & & 0.99 & 0.43 & & 0.99 & 0.39 & & 0.98 \\
\hline
\end{tabular}


hardly be able to play down this topic by using the VAA's importance ratings that range from $I$ to 3 .

Second, we can assess whether parties do in fact use these item importance ratings to align the implicit topic weights of the VAA with their own topic saliences as based on their electoral manifestos. This can be examined as follows: We first compare (by means of correlations) the topic importance profiles of the VAA, i.e. the implicit weights that are merely based on the item numbers under each topic with the parties' manifestobased topic importance profiles. Second, we do the same comparison but with the VAA topic importance profiles that were adjusted by the VAA-inherent topic importance ratings provided by the parties. We would expect that this second correlation of the topic salience profiles is higher for the parties if they use the VAA-internal weights to align the topic importance with their manifestos. On the other hand, parties might use the weights strategically and divert from the topic saliencies that are expressed through their manifestos. The results from these analyses are presented in Table 3.

The results indicate that there is no party that is systematically favored by the VAA item selection with regard to the topic weights. If anything, the highest correlations on average occur for the two catch-all parties SPÖ and ÖVP. However, for some elections, the smaller parties, too, show a moderate congruence of their manifesto-based topic weights with the VAA-inherent, implicit topic weights (Green Party in 2006, FPÖ and BZÖ in 2008). Moreover, the parties largely seem to use the VAA item weights in a way that aligns the VAA topic importance with the topic saliency they express through their electoral manifestos. There are also a number of instances in which this internal weighting does not lead to changes. However, in two cases, for the FPÖ and the Green Party in 2013, the correspondence in the topic weights drops visibly.

Finally, looking at the correlations in total, they are for the largest part weak to moderate. This means that parties' topic saliencies based on their manifestos are generally not reflected in the VAA item selection even after parties use VAA-internal weights to adjust the importance of VAA items and corresponding topics. Presuming that parties are generally intent on such an adjustment we conclude that the VAA item importance ratings are not adequate to achieve this. This, however, also means that the feature of party importance rating in the VAA is unlikely to fully serve the aim of optimizing the matching between user preferences and parties' programmatic profiles.

Altogether, combining the AUTNES data with the wahlkabine.at data holds two promises for making use of the VAA information. First, it can help to identify topics (and thus items) that are grossly over- or underrepresented in the VAA compared to the manifesto-based salience of these topics. The comparison in Table 2 furthermore suggests that using these manifesto-based saliences to weight the VAA items may lead to different party spaces that can be extracted from the VAA data. Second, the registered discrepancies in topic weights are especially important for the purpose of extracting party positions and interrelations because when doing so, one would like to take into account the importance given to the various policy issues by the parties themselves. The AUTNES data offer a substantially meaningful and methodologically well-founded basis for this purpose.

Table 3: Comparing the VAA-inherent topic importance profiles with topic importance in electoral manifestos (AUTNES data) as an external benchmark

\begin{tabular}{|c|c|c|c|c|c|c|}
\hline Election & 2006 & & 2008 & & 2013 & \\
\hline Party & no weighting & $\begin{array}{l}\text { with VAA-internal } \\
\text { party weights }\end{array}$ & no weighting & $\begin{array}{l}\text { with VAA-internal } \\
\text { party weights }\end{array}$ & no weighting & $\begin{array}{l}\text { with VAA-internal } \\
\text { party weights }\end{array}$ \\
\hline SPÖ & 0.48 & 0.64 & 0.46 & 0.50 & 0.33 & 0.58 \\
\hline ÖVP & 0.48 & 0.76 & 0.92 & 0.94 & 0.39 & 0.42 \\
\hline FPÖ & 0.09 & 0.25 & 0.78 & 0.81 & 0.36 & 0.26 \\
\hline BZÖ & 0.58 & 0.53 & 0.62 & 0.59 & 0.12 & 0.23 \\
\hline Grüne & 0.58 & 0.76 & 0.18 & 0.16 & 0.39 & 0.29 \\
\hline Team Stronach & & & & & 0.28 & 0.27 \\
\hline
\end{tabular}

Annotations: Values are Pearson correlation coefficients between the number of issues in wahlkabine.at assigned to one of the 13 AUTNES topics presented in table 1 (not weighted and weighted by the VAA internal issue saliency) and the share of these topics in the manifestos (AUTNES-data). Bold numbers represent change in the expected direction. 
Importantly, third, this source of topic weights is known and reproducible - in contrast to the implicit topic weights resulting from the selection of items in the VAA.

\section{Empirical analysis}

\subsection{Counting similarities}

In order to get a first impression of the data we look at a simple yet revealing descriptive statistic. ${ }^{2}$ Figure 2 presents the party similarities based on the raw data in the form of the percentage of items over the entire 25/26 wahlkabine.at-items a given party-couple agrees on (i.e. without any saliency-weighting). The highest agreement in every year is between the Green party and the leftist KPÖ. In 20I3, there was only one question they disagreed upon. With numbers of 15 to 25 percent, the lowest agreement can be found between the Green party and the KPÖ, on the one hand, and the FPÖ, BZÖ and (particularly since 20I3) the ÖVP, on the other hand.

Another interesting aspect concerns the ideological distance between ÖVP, SPÖ and FPÖ. While the agreement between the grand coalition parties dropped significantly from $62 \%$ in 2008 to $48 \%$ in 2013 , the agreement between each of these two parties and the rightwing populist FPÖ at the same time rose sharply (for the ÖVP by 22.2 , for the SPÖ by 9.8 percentage points). According to these data in 2017 (and already partly in 2013), a right-wing-populist coalition between ÖVP and FPÖ was ideologically more viable than a grand coalition. While this descriptive account is well suited to compare the distances between party pairs, they cannot provide a comprehensive picture of the ideological party space. For this purpose, the following section applies multidimensional scaling as a method to translate the pairwise similarities into spatial distances.

\subsection{Mapping the Austrian party system}

The information about the similarities and dissimilarities among all the parties based on the VAA items can be used to extract an overall structure of party interrelations. This works the better the more parties' positions on the various VAA items are systematically related to one another so that they can be broken down to a few dimensions (i.e. if parties that are opposed to one another on one item, e.g. concerning economic policy, are also opposed to one another on many other items, e.g. concerning environmental and welfare policy). These dimensions can then be used to describe the party policy space. In the following, we perform a dimension reduc-

2 We leave out the VAA for the 2002 election because only four parties were included for that election and thus the VAA provides too little information for making comparisons of their interrelations. tion of the data and extract party positions on these dimensions using multidimensional scaling (MDS). MDS uses information from a (dis-)similarity matrix that contains all pairwise comparisons between parties. Calculating these dissimilarities based on parties positions on the individual policy items allows for taking into account the item-specific weights described above (see figure I and tableI). The pattern of dissimilarities can then be condensed and visualized in low-dimensional spaces (Borg and Groenen 2005; Borg, Groenen, and Mair 20I3). The procedure minimizes the information loss that occurs through dimension reduction applied to the dissimilarity matrix. The lower the number of dimensions, the more information has to be condensed and the higher the information loss. ${ }^{3}$

In a first step, the distance matrix has been calculated using Gower's distance metric (Gower 197I), a generalized distance measure that allows for weighting the properties that enter into the calculation of the interobject distances. In a second step, performing the MDS, we choose a two-dimensional representation. This is not only justified by satisfactory low values for Stress-I $k$ O.I), which indicates the extent of information loss, but also allows for a straightforward and easily interpretable visual inspection. ${ }^{4}$ The selected MDS variant uses information on an interval scale and thus requires that not just the ordering but also the size of all the party dissimilarities is taken into account when translating them into spatial distances (Borg, Groenen, and Mair 2013, 38-39).

The scaling procedure will be done with four different kinds of data: (a) the unweighted, raw VAA data; (b) the weighted VAA data using the internal VAA party weights averaged over all parties - which applies a bird's eye view of the party space, emphasizing distances between parties if they concern issues rated as important on average by the parties; (c) the weighted VAA items using pairwise averaged internal VAA party weights - which presumes that the party space and party differences are seen from

3 While counting similarities is straightforward, this approach is not able to actually construct an ideological space. Cluster analysis may find certain patterns in the data, but its results largely depend on the applied clustering algorithm. Most importantly, MDS provides a multidimensional map of the party sphere that holds information on relative similarities and differences between parties, clusters of ideological close parties as well as dimensions that can be interpreted in a meaningful way - all in just one picture.

4 Additionally, the scree plots have been inspected for the results based on the 2006, 2008, and 2013 elections and using the manifesto-based weights. These plots contain the stress values for different numbers of dimensions used to represent the data are allow for checking whether there is a jump in the information loss when lowering the number of dimensions one by one. For the $2006 \mathrm{elec}-$ tion there is a clear elbow only for two dimensions, for 2008 there are elbows at two and four dimensions (but with comparatively the lowest stress values), and for 2013 there is again a clear elbow only at two dimensions. Together with the acceptable stress-I-values for two dimensions over all elections and the easier interpretation with a two-dimensional spatial representation, we take these to be suitable visualizations of the data. 
Figure 2: Programmatic agreement between parties based on the VAA data
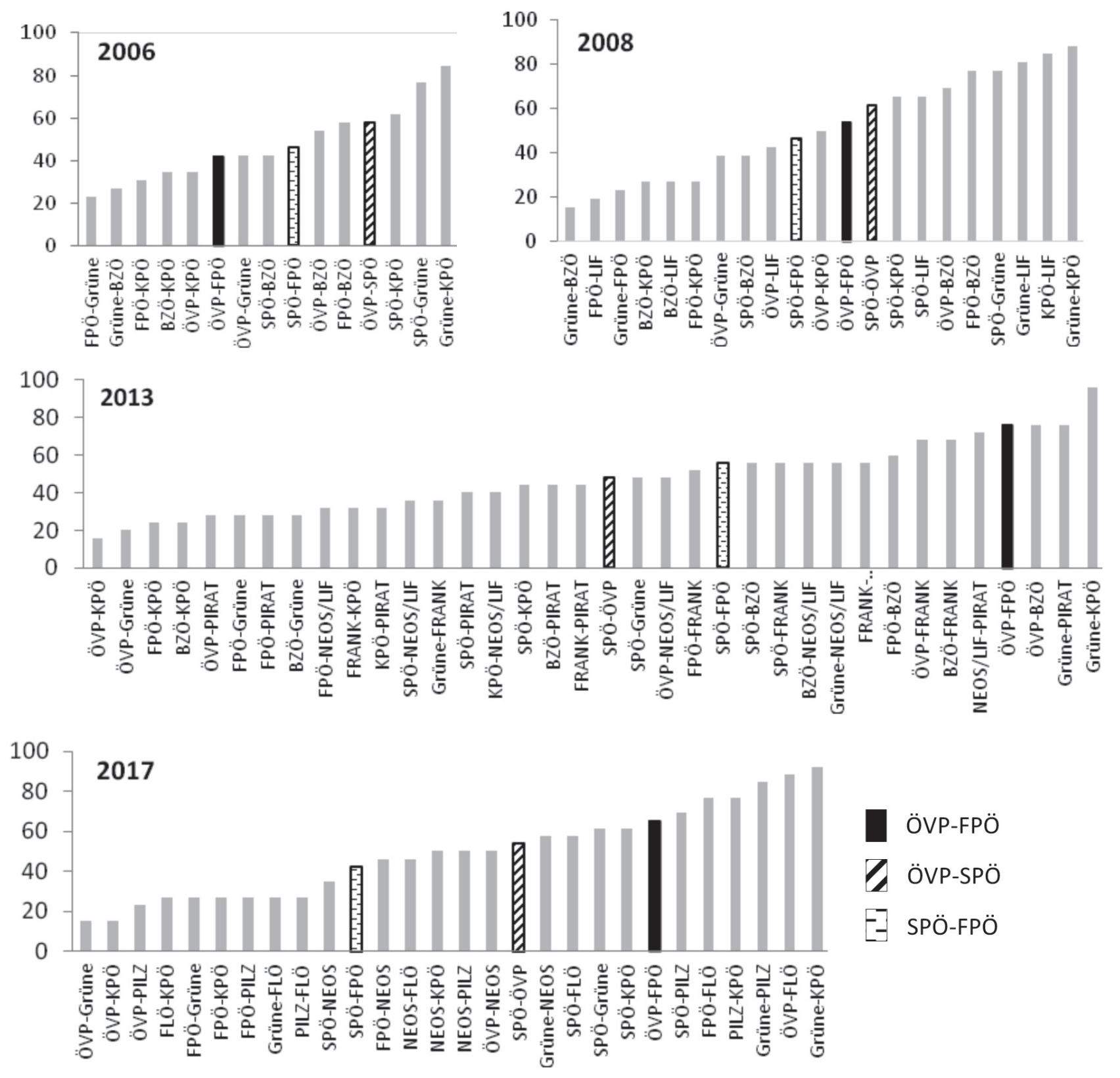

Party abbreviations: BZÖ = Bündnis Zukunft Österreich, Grüne = Die Grünen - Die Grüne Alternative, FLÖ = Freie Liste Österreich, FPÖ = Freiheitliche Partei Österreichs, FRANK = Team Stronach, KPÖ = Kommunistische Partei Österreichs, LIF = Liberales Forum, NEOS $=$ Das Neue Österreich und Liberales Forum, ÖVP = Österreichische Volkspartei, PILZ = Liste Peter Pilz, PIRAT = Piratenpartei Österreichs, SPÖ = Sozialdemokratische Partei Österreichs.

the point of view of party dyads $\left.s^{5}\right)$ and (d) weighted VAA items that are aligned with the overall topic weights in the party manifestos based on the external AUTNES coding data (for those elections for which the data is available). The examination proceeds in chronological order, starting with the 2006 election in Figure 3.

5 The idea is that only saliencies of the parties whose distance shall be calculated should be taken into account. Saliencies of other parties are not important with respect to this dyadic importance.
For the 2006 national election, we see a structure of party positions that appears overall valid. It shows the clear opposition between the leftist Parties Grüne and KPÖ together with the Social Democrats, on the one hand, and the ÖVP, BZÖ, and the FPÖ, on the other hand. The first dimensions thus can be interpreted as a general left-right dimension that combines socioeconomic as well as sociocultural items. The vertical dimension is harder to interpret. The items that primarily load on 
Figure 3: The Party Policy Space of the 2006 Austrian National Election

a) No weighting/raw VAA data

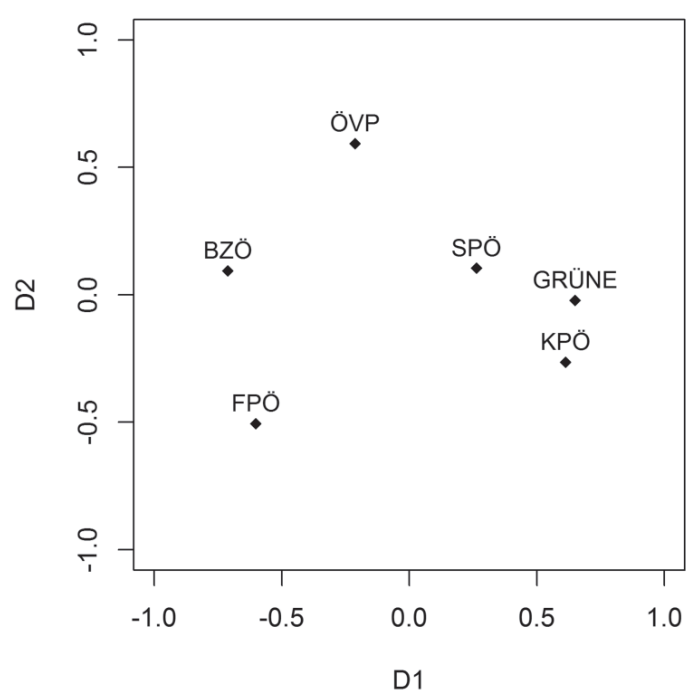

c) Internal weights (averaged pairwise)

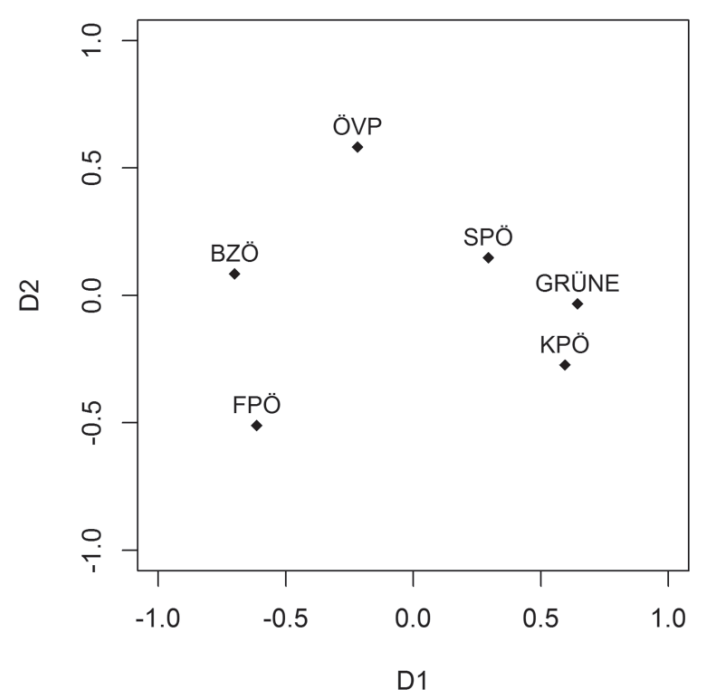

this dimension are the following three: Supporting child benefits in the existing form is correlated with higher values whereas support for stronger controls of banks and the introduction of universal income are correlated with lower values. These items all have in common that they refer to issues of major societal consensus, with parties rejecting this consensus located lower in the policy space.

It is furthermore notable that the parties in the left political spectrum are positioned relatively close together, whereas the other parties in the graphs are more heterogeneous. While this overall structure of party b) Internal weights
(averaged over all parties)

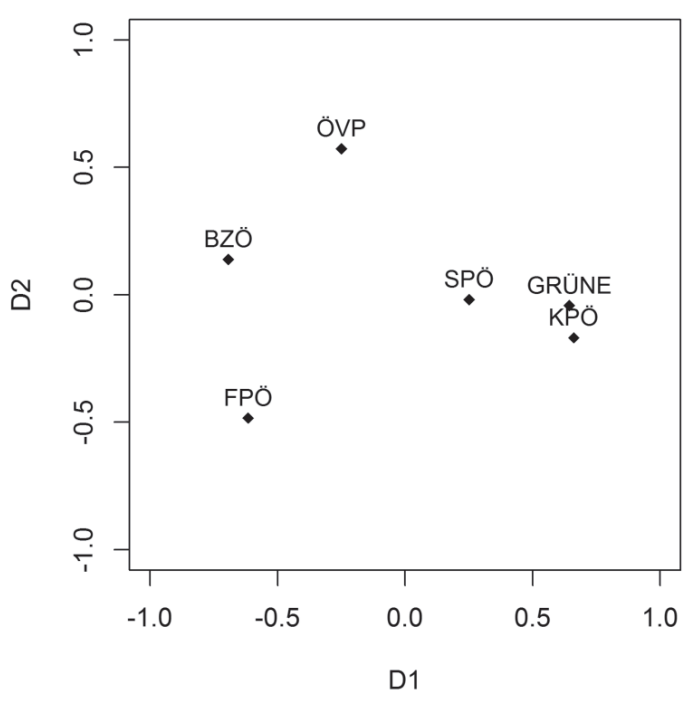

d) AUTNES-weights (manifestos)

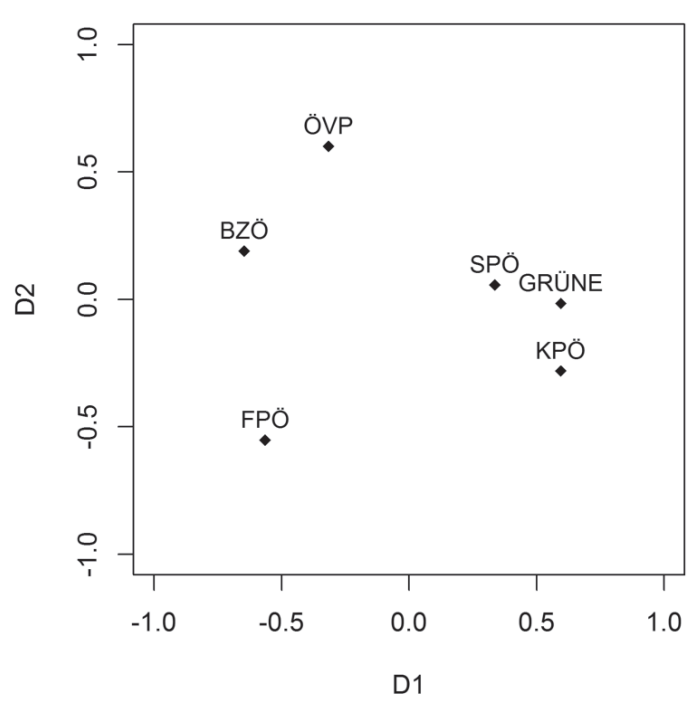

relations is present in all four graphs of Figure 3, the comparison of these four configurations also indicates that the results are visibly affected by the weighting of the VAA data. This primarily concerns the use of the internal weights averaged over all parties, which pulls the leftist parties closer together - a finding that is, however, not consistent with the pattern resulting from the external weights. In this latter case, the interrelations of the three leftist parties in the graph resemble the relations in the unweighted scaling configuration. Moreover, the external weights based on the party manifestos move the BZÖ closer to the ÖVP and away from the FPÖ. While 
Figure 4: The Party Policy Space of the 2008 Austrian National Election

a) No weighting/raw VAA data

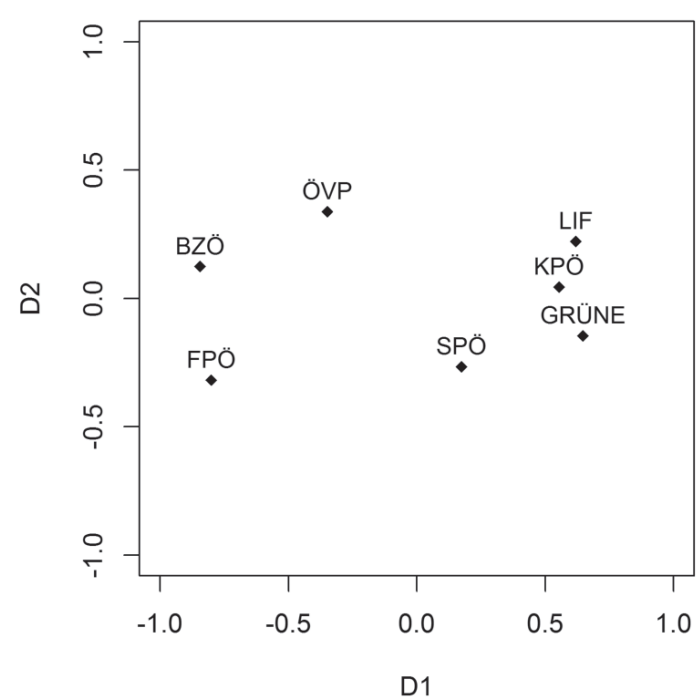

c) Internal weights (averaged pairwise)

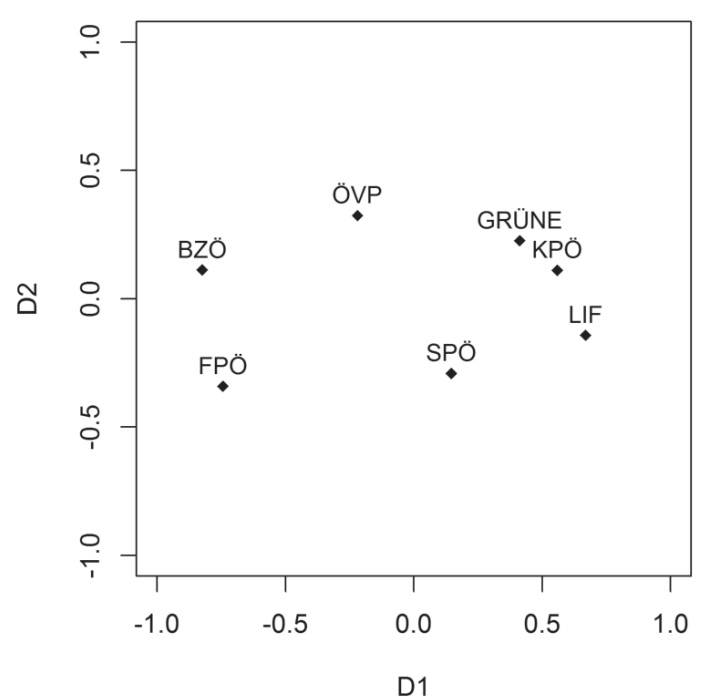

this does not alter the overall structure, it nevertheless changes the ranking of the programmatic affinities among the parties.

The results for the 2008 national election (Figure 4) appear overall consistent as well. Again, the weighting does not induce big changes in the party configuration. This also means, however, that it also does not allow for better discriminating between the three leftist parties on the right-hand side. Only in the solution that averages the pairwise internal party saliences in the VAA (c) they lie further apart. This, however, is a deviation from all the other configurations, particularly when looking b) Internal weights (averaged over all parties)

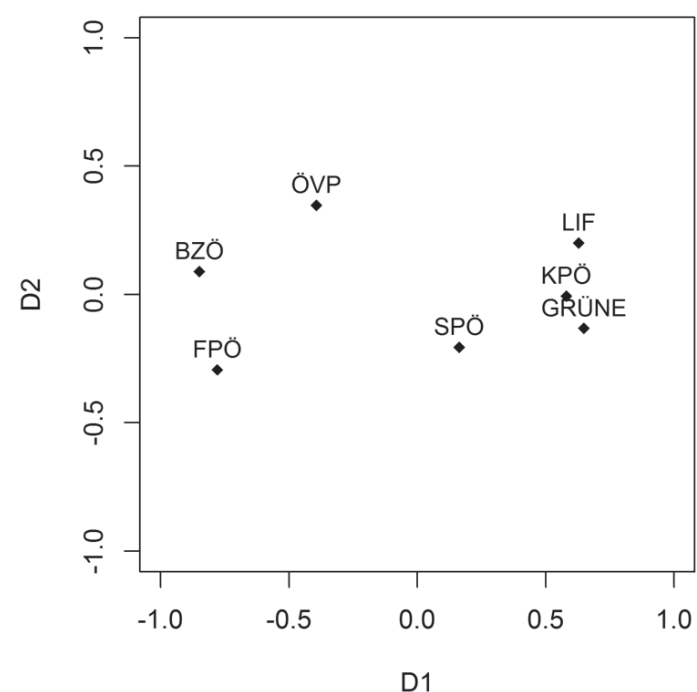

d) AUTNES-weights (manifestos)

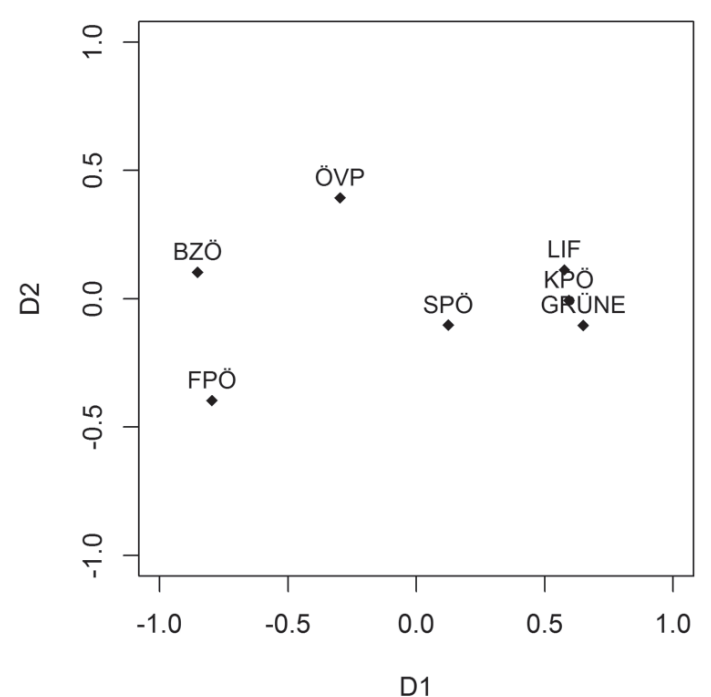

at the distance between the Green Party and the ÖVP. This distance is much lower if their dissimilarities are weighted by the averaged saliencies for these two parties only.

Altogether, it is reassuring that the dimensionality is highly similar to that in the 2006 election when looking at the party alignment. There is a cluster of leftist parties opposed by the three more heterogeneous parties that are located on the left-hand side of Figure 3, the ÖVP, $\mathrm{BZÖ}$, and FPÖ. On the vertical axis, when comparing the relative distances among the parties, this group of right-wing parties has moved closer together compared 
Figure 5: The Party Policy Space of the 2013 Austrian National Election

a) No weighting/raw VAA data

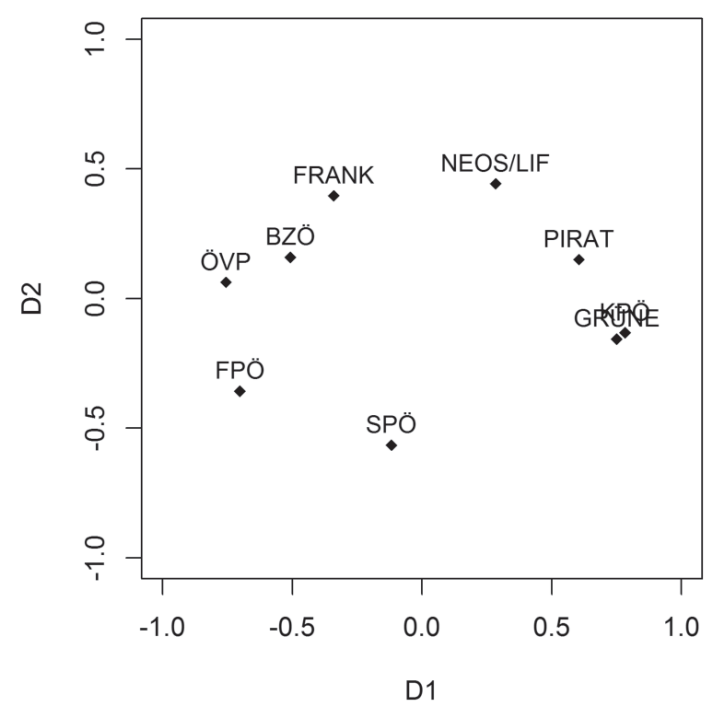

c) Internal weights (averaged pairwise)

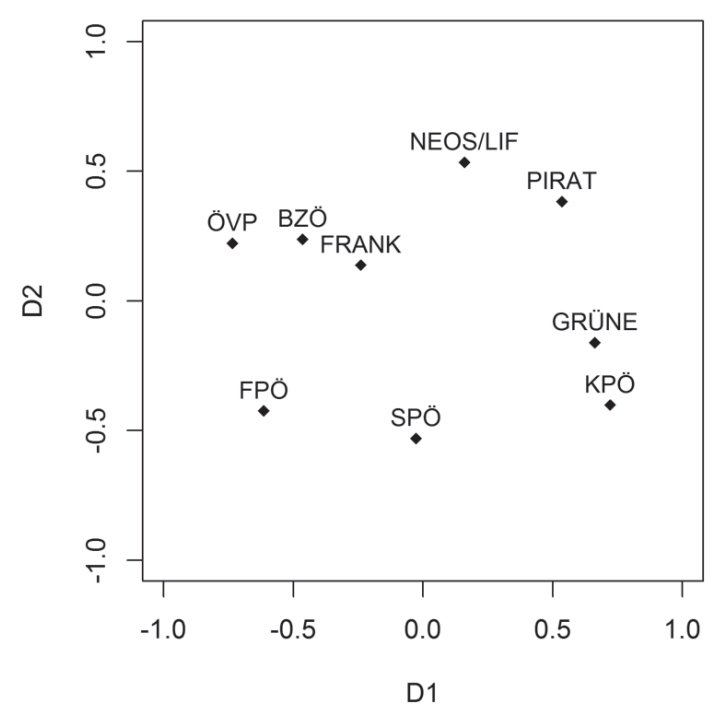

to 2006. Strikingly, this vertical dimension is again primarily marked by items that refer to issues concerning a clear societal consensus. While support for abolishing conscription and for the indexing of the retirement age to the demographic aging are represented by higher values, support for investments to obtain information about tax exiles is represented by lower values.

At the 2013 national election (Figure 5), we see a more complex field of parties with several new contenders that competed at the national level for the first time: the liberal party NEOS, the Pirate party, and the populist challenger party led by the Austrian-Canadian entre- b) Internal weights (averaged over all parties)

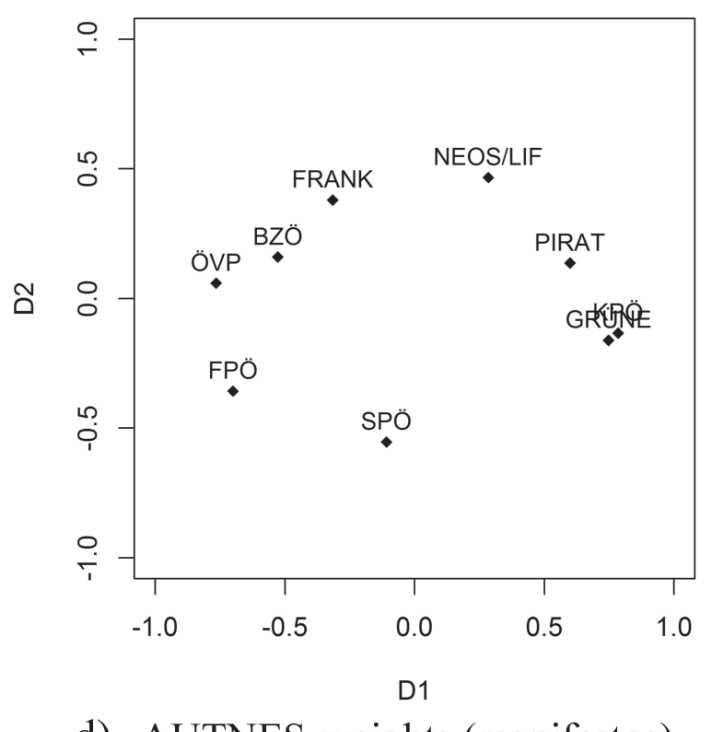

d) AUTNES-weights (manifestos)

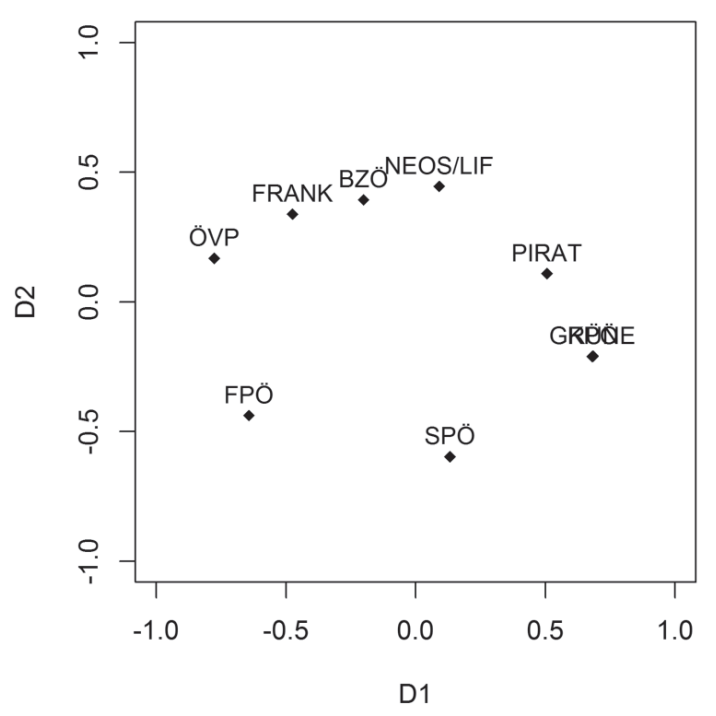

preneur Frank Stronach. The resulting party structure is not as clear-cut as the ones presented above. Strikingly, the leftist parties are now more heterogeneous too. A left cluster of the Green Party, the KPÖ, and the Pirate Party is still discernible, but the SPÖ now shows a greater or at least a similar affinity to the FPÖ, and to a lesser extent to the ÖVP, and to the BZÖ.

Only when using the VAA-internal party issue importance ratings and averaging these weights for all pairwise party comparisons individually (Figure 5c) does the SPÖ lie closer to the Green Party and the KPÖ - albeit not to the Pirate Party. A much more remark- 
able change occurs, however, with the manifesto-based weights. When looking at Figure $5 \mathrm{~d}$ in comparison to the two upper charts, one sees a switch in positions between the party of Frank Stronach and the BZÖ. This begs the question which the actual positions of the parties were at the election. Should we have more confidence in the internal weights or the external weights based on the manifestos? The results from the scaling analysis using the manifesto-based weights appears as the odd one out, but this result could, on the other hand, be seen as more accurate given that the distance between ÖVP and BZÖ is more similar to the corresponding distance in previ- ous elections. Yet, irrespective of the weighting, the BZÖ is not located between the ÖVP and FPÖ, as in previous elections. Moreover, the ÖVP takes the most extreme position at the opposite pole to the territory that is circumscribed by the leftist parties Green Party and KPÖ.

Finally, with regard to the results for the 2017 election (Figure 6), there are only marginal changes in the party policy space that result from the use of the internal weights. The results do not contain any anomalies, rather the overall pattern is highly similar to that of the preceding election, only with the minor parties BZÖ and Pirate Party missing. Correspondingly, the interpreta-

Figure 6: The Party Policy Space of the 2017 Austrian National Election

a) No weighting/raw VAA data

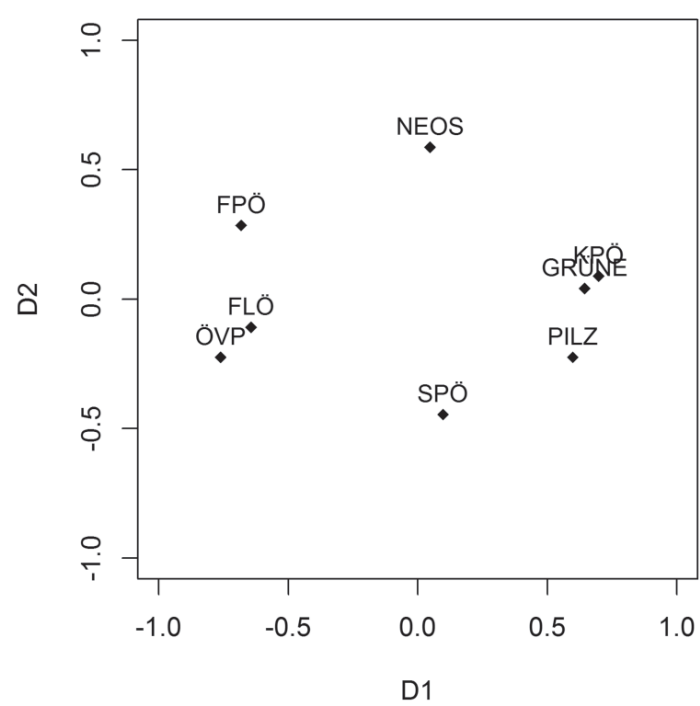

c) Internal weights (averaged pairwise)

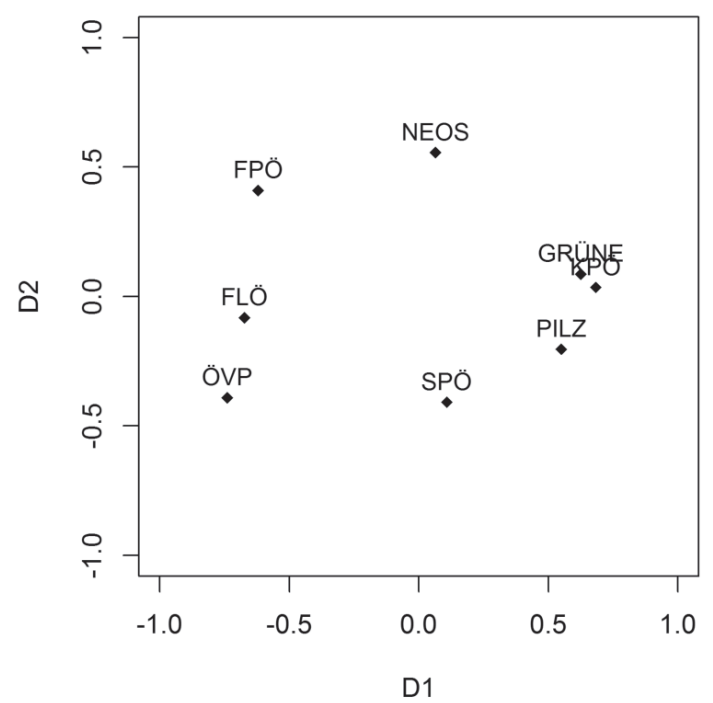

b) Internal weights (averaged over all parties)

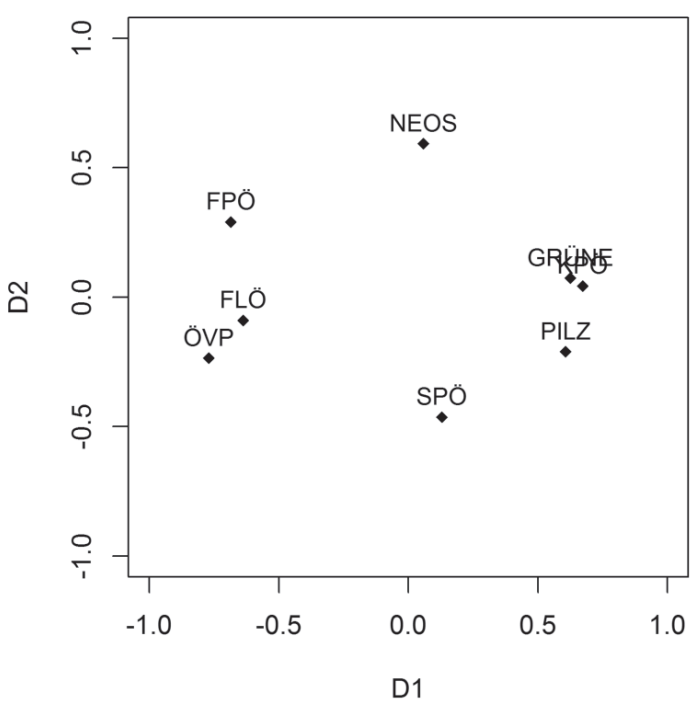


tion of the extracted ideological map is comparable to those for the other elections: The more to the left in the chart a party is located, the more economically market liberal and socio-culturally conservative it is. In addition, higher positions on the vertical axis represent party stances that reject status quo policies and cannot easily be mapped on the traditional left-right dimensions: support for abolishing the compulsive membership in the Austrian Federal Economic Chamber, support for state surveillance of online communication (such as the messenger Whatsapp), and support of state funding for socially polarizing art.

Against the backdrop of the pronounced similarities to the previous election, there are some noteworthy differences. While the SPÖ shows a greater affinity to the leftist cluster of the Green Party, the party Pilz that had split from the Green Party, and the KPÖ, the ÖVP is closer to the SPÖ at the 2017 election whereas the FPÖ is relatively more distant from the SPÖ than in 20I3. In that sense, we see a sort of normalization of Austrian party competition in terms of parties' policy positions when comparing them to the 2006 and 2008 elections and the comparatively deviant pattern for 2013 .

\subsection{Mapping the Austrian party system}

The period from 2006 to 2017 , covered in this article, represents the ultimate departure from the "hyperstable party system" (Wineroither and Kitschelt 2017, 25I) that characterized modern Austrian politics since 1945 (and particularly between 1970 and 1999), and constitutes a shift in the direction of a more fragmented and less concentrated party system. In 2006 for the last time, the grand-coalition parties each had more than 30 per cent in the national vote, whereas the Greens and the FPÖ consolidated their political weight. The following elections established these two smaller parties as relevant players on the Austrian political stage. In 20I7, the FPÖ came very close to its so far best result of nearly 27 percent under Jörg Haider in 1999. Additionally, with BZÖ, Team Stronach and NEOS, new parties have entered the arena.

The results of our analysis show that these major transformations at the level of the party system are also paralleled in significant alterations of the parties' relative positions within the political space. One major example here is the relative position of the FPÖ, which changed from being the odd one out to a position in 2013 that was closer to the ÖVP and the SPÖ than the two former grand coalition parties were to each other. This result may seem all the more astonishing as experts see Austria as an exemplary case for a programmatic convergence of the major parties (Wineroither and Kitschelt 20I7, 267). Yet there are also signs of convergence when looking at the change of the party configuration over time. The increasing relative proximity between FPÖ and SPÖ/ÖVP can only partly be ascribed to an active move of the right-wing populists - their large ideological shifts happened before 2006. It is also tied to the two grand coalition parties shifting away from their traditional locations in the overall party structure. This becomes particularly obvious in the case of the SPÖ, which in 2006 and 2008 can easily be located in the left camp (Greens, KPÖ and LIF) whereas in 20I3, it approached the more conservative positions held by FPÖ and ÖVP.

Finally, as a validity check of our results beyond pure face validity, we compared them to the data from the Chapel Hill Expert Survey (see appendix I for details). The overall structure of the party system is indeed highly congruent between our wahlkabine.at-based MDS-approach and the expert coding, thus bolstering our confidence in the validity of the chosen approach to map party positions based on (calibrated) VAA data. One noticeable difference to the Chapel Hill data should be noted though. In the Chapel Hill data the SPÖ virtually does not change their relative position throughout the observed years, while in our data the SPÖ in 2013 moves closer to the conservative block. This does not mean, however, that the findings presented above are inaccurate. Rather, as the expert ratings are likely to capture the more stable programmatic orientation of parties, the data used in the analysis above

\section{Conclusion}

Several conclusions can be taken away from the preceding analyses that concern the usefulness of VAAs and specifically the wahlkabine.at for extracting party policy spaces, but also the more general question of how scholars should interpret these party spaces and parties' positions.

First, the analysis has shown how the positional information about a considerable number of specific policy issues of the wahlkabine.at can be combined with information about the importance of these issues to extract party positions in a low-dimensional policy space. This approach thus uses more information than those approaches which either only use positional information or estimate party positions based on the relative issue emphasis by parties. It combines party positions regarding a range of concrete policy items that were relevant at a given election with comprehensive information about the saliencies of topics or issue domains. For the purpose of extracting party positions, it inherently makes sense to take into account both kinds of information. Party differences regarding policies that are only marginally relevant at an election can hardly be given the same weight as highly important issues when aiming to estimate overall party policy positions. The approach chosen above can be seen as an example of how to con- 
structively combine information about both positions and issue importance stemming from different sources.

Second, although the wahlkabine.at itself provides internal weights in the form of parties' issue importance ratings, these weights lead to negligible changes in the extracted policy spaces compared to the unweighted VAA data. The reason for this is that the party weights (on a scale between I and 3) effectively vary between 2 and 2.5. This is plausible as parties are not likely to publicly rate certain issues much less important than others. Using a larger scale (e.g. between I and IO, as it is, in fact, possible for the users of the Austrian VAA) would thus hardly be practically feasible as a way to improve the VAA-internal issue saliencies.

Hence, while parties may give more weight to some VAA items compared to others, these comparatively small differences cannot compensate for the selectivity of the items contained in the VAA which makes the internal weights also largely inadequate for calibrating the data in order to estimate party policy spaces. If a certain topic or issue dimension is grossly underrepresented among these items when compared to the election campaign and parties' manifestos, the internal weights are unable to address and correct this deficit sufficiently. The possible weighting range is simply too narrow to do justice to actual differences with regard to parties' communicated issue saliences. This conclusion is not only of relevance for generating and interpreting party policy spaces. It should be noted that the item importance ratings provided by the parties also enter into the calculation of matching scores provided to users of the VAA. As these importance ratings have virtually no bearing on the party spaces lying behind the VAA data, one might want to simply dismiss them anyway. However, if we presume that the feature of parties' own item importance rating has been purposefully included to improve the validity and accuracy of the data, then the results above might be reason for concern. Our results suggest that if they are supposed to correct any biases, they are not capable of doing that job.

Third, further doubts about the usefulness of the internal weights are raised by the fact that the topic saliencies expressed through parties' manifestos (based on the AUTNES data) markedly differ from the relative importance of topics represented in the VAA (based on the number of issues as well as based on the VAA-internal weights). The relative importance of topics inherent to the wahlkabine.at thus notably diverts from the saliences given by parties themselves and it is not clear which is the real or hypothetical source of saliences behind the VAA. Correspondingly, when weighting the VAA items with the manifesto-based weights, we see changes in the party spaces resulting from the scaling of the VAA items. Although the overall structure and major oppositions and affinities between parties remain intact, the relative dis- tances among some parties change considerably. These differences do not mean that these external weights per se lead to more accurate representations of party positions. However, they do imply that the party space inherent to the information contained in the wahlkabine. at is sensitive to the weighting of the data and scholars should be careful with their interpretations when analyzing Austrian party positions based on the unweighted data from the wahlkabine.at. Hence, the kind of weighting matters and combining issue weights with information about party positions regarding a range of policies is justified empirically given that this weighting has a bearing on the extracted party policy spaces - even though it does not affect the larger structure of party positions.

Moreover, and fourth, drawing on external data sources, such as the AUTNES data, for weighting policy items can generally serve to calibrate the VAA data through aligning the implicit weights of topics represented by the VAA - the sources of which are unknown - with known and easily interpretable external issue importance scores. It should be stressed that the external weighting we used in the analysis is clearly not some far-fetched hypothetical. Rather, it is based on easily interpretable and reproducible topic saliences that can be defended as a measure of the importance that parties give to certain topics themselves through their manifestos. Moreover, while the issue emphasis in manifestos is clearly the product of party intentions, decisions and strategies, it is less amenable to short-term tactical distortions than it is providing answers about issue importance for VAAs. This is no minor issue because parties have an incentive to give answers that will best serve their purpose at the election (Krouwel, Vitiello, and Wall 2012, 235).

However, in order to be able to calibrate the data contained by the VAA and balance an undue weight/salience of certain issues by means of external weights, all relevant topics should be covered by the VAA. If issues that are overall relevant in the party manifestos are not represented in the VAA, no weighting scheme will be able to correct for such an omission. Indeed, when looking at the AUTNES categories, there are major topics that were not covered by the VAA, e.g. the European Union issue at the 2013 election. Yet, leaving a certain topic out does not amount to a problem under all conditions. As long as other important issues are represented which correlate with those that were left out (i.e. parties take similar positions as on those items that are not represented, e.g. on foreign policy and European Union affairs), it is theoretically still possible to yield valid overarching issue dimensions using scaling procedures.

Beyond questions of VAA design, the results presented above hold a further important conclusion. The general idea of using weights to calibrate party policy spaces directly points to an inherent perspectivism in- 
volved in these spaces. When thinking about how to weigh the policy items of a VAA properly in order to get the party positions and interrelations right, the question is also what getting it right means. This depends on which policy space and which underlying perspective is of interest. The analysis above has used the issue weights as expressed by parties themselves through their manifestos. This can be seen as only one perspective among other possible ones, but it is one that is intelligible and reproducible and allows for making statements about the structure of party relations when presuming a global perspective of issue saliences anchored in the level of parties themselves. However, different perspectives could also be of interest. For instance, one could draw on issue weights as communicated through media reporting about an election. These issue saliences conveyed through the media might even differ depending on the outlet. In that regard our results might also be of interest for the question how political positions are communicated within electoral campaigns and thus for the field of (political) communication and marketing studies in general (see for example Seethaler and Melischek 20I4). It is furthermore conceivable to simulate certain sub-groups of the population that show very clear issue priorities. From the perspective of such issue publics, groups of people who are only interested in a few issues or just one specific issue (Converse 2006), the party policy spaces may look quite different from the ones presented further above. And just like voters may stress certain issues, parties too may focus on only few or a single issue (although we did not find signs of such a party in the analysis above). Given their programmatic emphasis, the way that such parties distinguish themselves from other parties and their view of the entire party policy space also arguably differs from the spatial representations presented further above.

All in all, the idea of being able to bring different weights to policy positions implies that party policy spaces have to be interpreted in terms of the underlying perspective that scholars should be aware of. The approach pursued above furthermore opens up ways to bring different perspectives to the structure of parties' policy positions in order to better understand certain aspects of party politics and party competition. Following this notion of perspectivism, the fact that we found the implicit topic weights of the wahlkabine.at to considerably deviate from the topic saliences expressed through parties' electoral manifestos does not as such constitute a problem. Rather, what is problematic is that we do not know what the topic weights resulting from the mere selection of VAA items are supposed to represent. What is the underlying perspective that the VAA designers had in mind? This aspect should be taken seriously as it potentially not only concerns the party policy spaces generated from the VAA data but also the party-user matches the VAA provides. Greater transparency in that respect would help to literally put the programmatic party differences and party-user matches respectively into perspective - a requisite that is of relevance not just for the Austrian wahlkabine.at but for VAAs in general.

\section{References}

Agathokleous, Marilena/Nicolas Tsapatsoulis (2016), Applying Hidden Markov Models to Voting Advice Applications, in: EPJ Data Science, Vol. 5 (I), Internet: https://doi.org/IO.II40/epjds/sI3688-0I6-0095-z.

Benoit, Kenneth/Michael Laver (2006), Party Policy in Modern Democracies, London: Routledge.

Borg, Ingwer/Patrick J. F. Groenen (2005), Modern Multidimensional Scaling: Theory and Applications, 2nd ed., New York: Springer.

Borg, Ingwer/Patrick J. F. Groenen/Patrick Mair (2013), Applied Multidimensional Scaling, Berlin: Springer.

Bornschier, Simon (2010), The New Cultural Divide and the Two-Dimensional Political Space in Western Europe, in: West European Politics, Vol. 33 (3), 419-44, Internet: https://doi.org/IO.IO80/oI402381003654387.

Converse, Philip E. (2006), The Nature of Belief Systems in Mass Publics (1964), in: Critical Review, Vol. I8 (I-3), I-74, Internet: https://doi. org/I0.1080/08913810608443650.

Dolezal, Martin/Laurenz Ennser-Jedenastik/Wolfgang C. Müller/Anna Katharina Winkler (2016), Analyzing Manifestos in Their Electoral Context A New Approach Applied to Austria, 2002-2008, in: Political Science Research and Methods, Vol. 4 (3), 64I-50, Internet: https://doi.org/IO.IOI7/psrm.2015.38.

Fivaz, Jan/Giorgio Nadig (2010), Impact of Voting Advice Applications (VAAs) on Voter Turnout and Their Potential Use for Civic Education, in: Policy \& Internet, Vol. 2 (4), I67-200, Internet: https://doi. org/IO.2202/1944-2866.IO25.

Gemenis, Kostas (2013a), Estimating Parties' Policy Positions through Voting Advice Applications: Some Methodological Considerations, in: Acta Politica, Vol. 48 (3), 268-95.

- - (2013b), Estimating Parties' Policy Positions through Voting Advice Applications: Some Methodological Considerations, in: Acta Politica, Vol. 48 (3), 268-95, Internet: https://doi.org/IO.IO57/ap.20I2.36.

Germann, Micha/Fernando Mendez/Jonathan Wheatley/ Uwe Serdült (2015), Spatial Maps in Voting Advice Applications: The Case for Dynamic Scale Validation, in: Acta Politica, Vol. 50 (2), 214-38, Internet: https://doi. org/IO.IO57/ap.2OI4.3.

Gower, J. C. (1971), A General Coefficiant of Similarity and Some of Its Properties, in: Biometrics, Vol. 27 (4), $857-7$ I. 
Katakis, Ioannis/Nicolas Tsapatsoulis/Fernando Mendez/ Vasiliki Triga/Constantinos Djouvas (2014), Social Voting Advice Applications, Definitions, Challenges, Datasets and Evaluation, in: IEEE Transactions on Cybernetics, Vol. 44 (7), I039-52, Internet: https://doi. org/IO.IIO9/TCYB.2OI3.2279019.

Kleinnijenhuis, Jan/Jasper van de Pol/Anita MJ van Hoof/ André PM Krouwel (2017), Genuine Effects of Vote Advice Applications on Party Choice: Filtering out Factors That Affect Both the Advice Obtained and the Vote, in: Party Politics, July, Internet: https://doi. org/IO.II77/135406881771312I.

König, Pascal D./Sebastian Jäckle (2018), Voting Advice Applications and the Estimation of Party Positions - A Reliable Tool? in: Swiss Political Science Review, Vol. 24 (2), I87-203. Internet: https://doi.org/ro.IIII/ spsr.I230I

Kriesi, Hanspeter/Edgar Grande/Romain Lachat/Martin Dolezal/Simon Bornschier/Timotheos Frey (2006), Globalization and the Transformation of the National Political Space: Six European Countries Compared, in: European Journal of Political Research, Vol. 45 (6), 92I-56, Internet: https://doi.org/IO.IIII/j.I4756765.2006.00644.x.

Krouwel, André/Thomas Vitiello/Matthew Wall (2012), The Practicalities of Issuing Vote Advice: A New Methodology for Profiling and Matching, in: International Journal of Electronic Governance, Vol. 5 (3/4), 223, Internet: https://doi.org/IO.1504/IJEG.2012.051308.

Ladner, Andreas (2016), Do VAAs Encourage Issue Voting and Promissory Representation? Evidence From the Swiss Smartvote: VAAs, Issue Voting, and Promissory Representation, in: Policy \& Internet, Vol. 8 (4), 412-30, Internet: https://doi.org/IO.IOO2/poi3.I37.

Laver, Michael/John Garry/Kenneth Benoit (2007), Wordscores. https://www.tcd.ie/Political_Science/wordscores/ (Accessed: 02.05.2019).

Laver, Michael/W. Ben Hunt (1992), Policy and Party Competition, New York: Routledge.

Louwerse, Tom/Martin Rosema (2014), The Design Effects of Voting Advice Applications: Comparing Methods of Calculating Matches, in: Acta Politica, Vol. 49 (3), 286-312.

Mahéo, Valérie-Anne (2016), The Impact of Voting Advice Applications on Electoral Preferences: A Field Experiment in the 2014 Quebec Election: The Impact of VAAs on Electoral Preferences, in: Policy \& Internet, Vol. 8 (4), 39I-4II, Internet: https://doi.org/IO.IOO2/ poi3.I38.

Marschall, Stefan/Martin Schultze (2012), Voting Advice Applications and Their Effect on Voter Turnout: The Case of the German Wahl-O-Mat, in: International Journal of Electronic Governance, Vol. 5 (3/4), 349, Internet: https://doi.org/IO.I504/IJEG.2OI2.05I3I4.
Müller, Wolfgang C./Anita Bodlos/Martin Dolezal/Nikolaus Eder/Laurenz Ennser-Jedenastik/Matthias Kaltenegger/Thomas M. Meyer/Katrin Praprotnik/Anna Katharina Winkler (20I7), AUTNES Content Analysis of Party Manifestos 20I3. GESIS Data Archive, Internet: https://doi.org/IO.4232/I.I 2752.

Müller, Wolfgang C./Franz Fallend (2004), Changing Patterns of Party Competition in Austria: From Multipolar to Bipolar System, in: West European Politics, Vol. 27 (5), 80I-835, Internet https://doi.org/IO.IO80/oI4 0238042000283319.

Müller, Wolfgang C./Marcelo Jenny (2000), Abgeordnete, Parteien Und Koalitionspolitik. Individuelle Präferenzen Und Politisches Handeln Im Nationalrat, in: Austrian Journal of Political Science, Vol. 29 (2), I37-56.

Naumann, Florian (2017), Wahl-O-Mat-Auswertung: Diese Partei Stimmt Am Stärksten Mit Der AfD Überein, in: Merkur.de, 9 September 2017, Internet: https://www.merkur.de/politik/bundestagswahl20I7-wahl-o-mat-auswertung-diese-partei-hatgroesste-uebereinstimmung-mit-afd-zr-8668627. html (Accessed: 02.05.2019).

Polk, Jonathan/Jan Rovny/Ryan Bakker/Erica Edwards/ Liesbet Hooghe/Seth Jolly/Jelle Koedam, et al. (20I7), Explaining the Salience of Anti-Elitism and Reducing Political Corruption for Political Parties in Europe with the 2014 Chapel Hill Expert Survey Data, in: Research \& Politics, Vol. 4 (I), Internet: https://doi. org/IO.1177/2053168016686915.

Praprotnik, Katrin (2015), Die Policy-Bilanz Der Regierung Faymann I. Ein Test Der Mandatstheorie, in: Österreichische Zeitschrift Für Politikwissenschaft, Vol. 44 (2), I, Internet: https://doi.org/IO.15203/ozp.457. vol44iss2.

Proksch, Sven-Oliver/Jonathan B. Slapin (2009), WORDFISH. Scaling Software for Estimating Political Positions from Texts (version I.3 (22.01.2009), Internet: http://www.wordfish.org/ (Accessed: 02.05.2019)

Rosema, Martin/Tom Louwerse (2016), Response Scales in Voting Advice Applications: Do Different Designs Produce Different Outcomes?: Response Scales in Voting Advice Applications, in: Policy \& Internet, Vol. 8 (4), 43I-56, Internet: https://doi.org/IO.IOo2/ poi3.I39.

Schermann, Katrin/Laurenz Ennser-Jedenastik (2OI4a), Coalition Policy-Making under Constraints: Examining the Role of Preferences and Institutions, in: West European Politics, Vol. 37 (3), 564-83, Internet: https:// doi.org/I0.1080/0I402382.2013.841069.

- - (20I4b), Explaining Coalition-Bargaining Outcomes: Evidence from Austria, 2002-2008, in: Party Politics, Vol. 20 (5), 79I-80I, Internet: https://doi. org/IO.II77/I354068812453373. 
Schultze, Martin (2014), Effects of Voting Advice Applications (VAAs) on Political Knowledge About Party Positions: Effects of VAAs on Political Knowledge About Party Positions, in: Policy \& Internet, Vol. 6 (I), 46-68, Internet: https://doi.org/Io.IOO2/1944-2866. POI352.

Seethaler, Josef/Gabriele Melischek (2014), Phases of Mediatization: Empirical Evidence from Austrian Election Campaigns since I970, in: Journalism Practice, Vol. 8 (3), 258-78, Internet: https://doi.org/IO.IO8 O/I75I2786.20I4.889443.

Talonen, Jaakko/Mika Sulkava (20II), Analyzing Parliamentary Elections Based on Voting Advice Application Data, in: João Gama/Elizabeth Bradley/Jaakko Hollmén (ed.), Advances in Intelligent Data Analysis $\mathrm{X}$ : IDA 2OII. Lecture Notes in Computer Science, Vol. 70I4, Berlin: Springer, 340-5I.

Volkens, Andrea (2007), Strengths and Weaknesses of Approaches to Measuring Policy Positions of Parties, in: Electoral Studies, Vol. 26 (I), I08-I20, Internet: https://doi.org/IO.IOI6/j.electstud.2006.04.003.

Volkens, Andrea/Pola Lehmann/Theres Matthieß/Nicolas Merz/Sven Regel/Bernhard Weßels/WZB Berlin Social Science Center (20I7), Manifesto Project Dataset: Manifesto Project, Internet: https://doi.org/Io.25522/ manifesto.mpds.20I7a.

Wagschal, Uwe/Pascal König (20I4), Alle Gleich? Analyse Der Programmatischen Parteiunterschiede Bei Bundestagswahlen Auf Basis Der Wahl-O-Mats, in: Zeitschrift Für Parlamentsfragen, Vol. 45 (4), 865-84.

wahlkabine.at. (20I7), Erläuterungen Zur Umsetzung Und Methodik,Internet:https:/wahlkabine.at/downloads/ Wahlkabine_Methodik_NRW2oI7.pdf (Accessed: 02.05.2019).

Walgrave, Stefaan/Peter van Aelst/Michiel Nuytemans (2008), "Do the Vote Test": The Electoral Effects of a Popular Vote Advice Application at the 2004 Belgian Elections, in: Acta Politica, Vol. 43 (I), 50-70, Internet: https://doi.org/IO.IO57/palgrave.ap.5500209.

Warwick, Paul V. (2006), Policy Horizons and Parliamentary Government, Basingstoke: Palgrave Macmillan.

Wheatley, Jonathan (2012), Using VAAs to Explore the Dimensionality of the Policy Space: Experiments from Brazil, Peru, Scotland and Cyprus, in: International Journal of Electronic Governance, Vol. 5 (3/4), 318-48.

Wheatley, Jonathan/Christopher Carman/Fernando Mendez/James Mitchell (2014), The Dimensionality of the Scottish Political Space: Results from an Experiment on the 2or Holyrood Elections, in: Party Politics, Vol. $20(6), 864-878$.

Wineroither, David M./Herbert Kitschelt (2017), Die Entwicklung des Parteienwettbewerbs in Österreich im internationalen Vergleich, in: Ludger Helms/David M. Wineroither (ed.), Die österreichische Demokratie im
Vergleich, 2nd ed., Baden-Baden: Nomos Verlagsgesellschaft mbH \& Co. KG, 25I-285, Internet: https:// doi.org/IO.577I/9783845239163-I93.

\section{Authors}

Sebastian Jäckle is a political scientist working at the University of Freiburg, Germany. In his recent research he focuses on political elites, anti-immigrant violence, and appearance effects in elections. His work has also appeared in West European Politics, Legislative Studies Quarterly, the Hournal of European Public Policy and European Sociological Review.

Pascal D. König is researcher at the Institute of Political Science at the Goethe-University Frankfurt, Germany. His research mainly deals with political communication, party competition, and policies regarding digital technologies. Recent work has appeared in Journal of European Public Policy, Party Politics, European Sociological Review, and Review of Policy Research. 